\title{
The biological role of actinin-4 (ACTN4) in malignant phenotypes of cancer
}

\author{
Kazufumi Honda $a^{1,2^{*}}$
}

\begin{abstract}
Invasion and metastasis are malignant phenotypes in cancer that lead to patient death. Cell motility is involved in these processes. In 1998, we identified overexpression of the actin-bundling protein actinin-4 in several types of cancer. Protein expression of actinin-4 is closely associated with the invasive phenotypes of cancers. Actinin-4 is predominantly expressed in the cellular protrusions that stimulate the invasive phenotype in cancer cells and is essential for formation of cellular protrusions such as filopodia and lamellipodia. ACTN4 (gene name encoding actinin-4 protein) is located on human chromosome 19q. ACTN4 amplification is frequently observed in patients with carcinomas of the pancreas, ovary, lung, and salivary gland, and patients with ACTN4 amplifications have worse outcomes than patients without amplification. In addition, nuclear distribution of actinin-4 is frequently observed in small cell lung, breast, and ovarian cancer. Actinin-4, when expressed in cancer cell nuclei, functions as a transcriptional co-activator. In this review, we summarize recent developments regarding the biological roles of actinin-4 in cancer invasion.
\end{abstract}

Keywords: Cancer invasion, Metastasis, Actinin-4 (ACTN4), Actin-bundling protein, Biomarker

\section{Background}

Despite successful complete resection at the primary cancer site, poor outcomes are occasionally observed in patients due to failure to control distant metastasis. Controlling metastasis is expected to improve the survival rate of patients with cancer $[1,2]$. The mechanisms of cancer metastasis, which occurs in a multistep process, have been investigated to identify new therapeutic strategies for patients with cancer. During formation of metastatic lesions, carcinoma cells destroy the basement membrane, invade the surrounding extracellular matrix, intravasate through the endothelium into the circulation, extravasate again though the capillary vessels, and finally establish secondary tumors at distant sites $[1,3,4]$. The dynamic assembly of the actin cytoskeleton is important in this multistep process of forming metastatic lesions. In particular, the actin cytoskeleton plays important roles in the formation of cellular protrusions known as filopodia, lamellipodia, and invadopodia [5-10].

\footnotetext{
*Correspondence: khonda@ncc.go.jp

${ }^{1}$ Department of Chemotherapy and Clinical Research, National Cancer Center Research Institute, 5-1-1 Tsukiji Chuoku, Tokyo 104-0045, Japan Full list of author information is available at the end of the article
}

Alpha-actinin is an actin cross-linking protein that belongs to the spectrin superfamily. Four isoforms of alpha-actinin have been identified: alpha-actinin-1 (gene name; ACTN1) [11], actinin-2 (ACTN2) [12], actinin-3 (ACTN3) [12], and actinin-4 (ACTN4) [13]. These isoforms are classified into two groups: muscle (ACTN2 and ACTN3) and non-muscle isoforms (ACTN1 and ACTN4) [14]. Muscle-type isoforms of actinins are only expressed in skeletal and smooth muscle, where they mediate actin filament bundling and interactions with the Z-disk. On the other hand, non-muscle type isoforms are only expressed in non-muscle cells, where they also mediate actin filament bundling and interact with cell membranes. Non-muscle types in particular are associated with cell adhesion and cell migration. We originally identified ACTN4 as a metastasis-related gene in cancer in 1998 [13] and have investigated the biological mechanisms and clinical implications of actinin-4 in cancer metastasis.

In this review, I mainly describe the involvement of actinin-4 in cancer metastasis and review recent studies of the biological function of actinin- 4 in cancer and human diseases. 


\section{Isolation of ACTN4, a metastasis-related gene}

We generated a mouse monoclonal antibody that strongly reacts to the highly invasive phenotype of breast carcinoma, and we identified the full-length cDNA for the protein that was recognized by this antibody. This cDNA encodes a fourth novel isoform of alpha-actinin and was named actinin-4. Human actinin-4 is composed of 911 amino acids, and the amino acid homology with actinin-1 is $86 \%$ [13]. Alpha-actinin family members form an anti-parallel dimer with an actin-binding domain (ABD), which is composed of two calponin homology $(\mathrm{CH})$ domains at the $\mathrm{N}$-terminus of each monomer. Adjacent to the $\mathrm{ABD}$, four spectrin repeats are followed by a C-terminal calmodulin (CaM)-like domain consisting of two EF-hand repeats (Fig. 1a) [14]. This molecular architecture results in the formation of a rod-shaped molecule with $\mathrm{ABD}$ and $\mathrm{CaM}$ domains at both ends, allowing cross-linking of bundles of actin filaments (Fig. 1b). Moreover, non-muscle alpha-actinins interact with actin filaments to connect with the plasma membrane through beta 1-3 integrins, vinculin, and alpha-catenin (Fig. 1c) [14-16].

Immunohistochemical analysis with the anti-actinin4-specific antibody revealed significant overexpression of actinin-4 in histological subtypes of breast cancer with high invasive ability. Patients with overexpression of actinin-4 in invasive ductal adenocarcinoma of the breast show worse prognosis for overall survival than patients without overexpression. Immunocytochemistry following the wound healing assay to evaluate the invasiveness of cancer cells revealed that actinin-4 predominantly accumulates at artificial invasive fronts [13].

a

Actin-binding domain

Two EF-hand motifs (ABD)

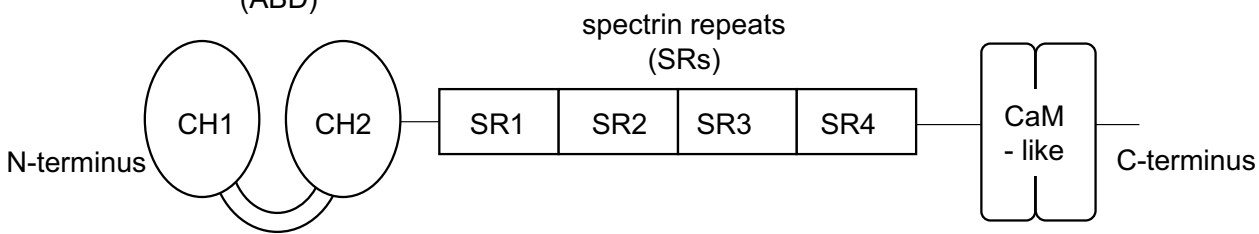

Calponin

homology $(\mathrm{CH})$

domain

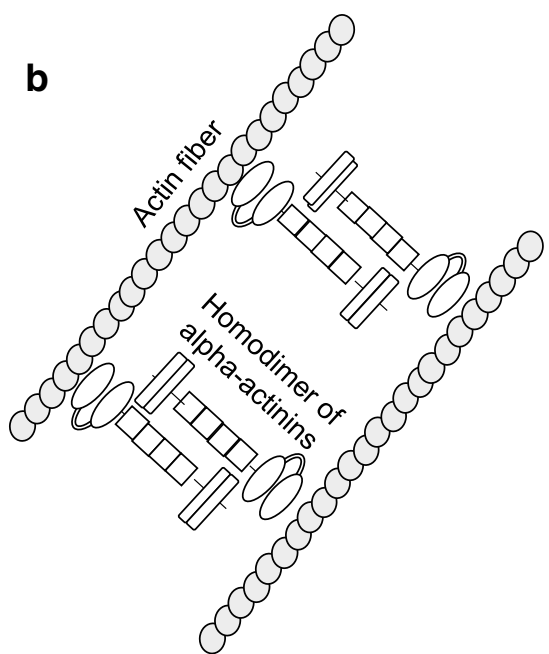

Calmodulin

(CaM)-like

domain

\section{C}

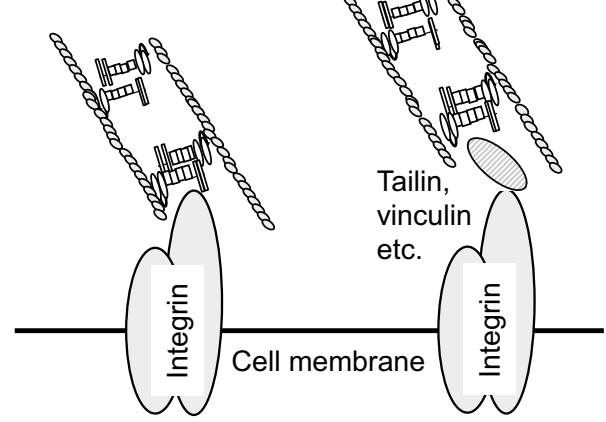

Fig. 1 Schematic of the domain structure of alpha-actinins (a). Alpha-actinins are composed of an actin-binding domain (ABD), four spectrin repeats (SRs), and a calmodulin (CaM)-like domain. ABDs are composed of two calponin homology (CHs) domains (CH1 and $\mathrm{CH} 2)$. $\mathrm{CaM}$-like domains are composed of two EF-hand motifs. Schematic of actin bundling with alpha-actinins (b). Actinins form an anti-parallel dimer, and homodimers of actinins bundle actin fibers by interacting with the ABD. Schematic of interactions between actin fibers and cell membranes (c). Actin fibers bundled with actinins directly or indirectly interact with the cell membrane through integrins. 


\section{The correlation between protein overexpression of actinin-4 and metastatic ability of cancer cells}

Cancer cells, which are at the invasive front of cancer tissues, show an increased ability to migrate and metastasize, and show loss of epithelial integrity and specialization, a phenotype known as epithelial to mesenchymal transition (EMT) [10, 17]. Cells at the invasive fronts of colorectal cancer show reduced expression of E-cadherin, lose their cell-cell adhesions, and aggressively invade the stroma [18-21]. In colorectal cancer, overexpression of actinin-4 and EMT are observed in cells at the invasive front. We generated colorectal cancer cells (DLD1-TetOff-ACTN4) that express N-terminal HAtagged actinin-4 under control of the tetracycline regulatory system and confirmed the distribution of exogenous actinin-4 with immunocytochemistry. When exogenous actinin-4 was overexpressed in DLD1-TetOff-ACTN4 cells, filopodia and lamellipodia, which are involved in cell migration, were predominantly observed on the cell surface compared with before overexpression. DLD1TetOff-ACTN4 cells are highly motile in a cell motility assay, and animal experiments to confirm the metastatic ability revealed a significant increase in lymph node metastases compared with control cells [22]. On the other hand, an siRNA-mediated decreased in actinin-4 protein in a colon cancer cell line (SW480) reduces the cellular protrusions that are associated with cancer invasion [23].

Similar phenomena are observed in pancreatic cancer. Overexpression of actinin- 4 is observed in invasive ductal adenocarcinoma of the pancreas, and such patients have a worse prognosis for overall survival than patients with weak actinin-4 expression [24]. In addition, actinin-4 is mainly observed at the invadepodia of cells from a pancreatic cancer cell line [25]. When actinin-4 is reduced in the pancreatic cancer cell line, BxPC3-KD-ACTN4, with ACTN4 siRNA, the invasive ability in the invasion assay is decreased [23]. Transplantation of pancreatic cancer cells with siRNA-mediated reduction of ACTN4 expression into the pancreas of mice revealed no destructive invasion into the pancreas compared with control cells. Patients with ovarian cancer with overexpression of actinin-4 show similar results, including a worse outcome than patients without overexpression [26].

Interestingly, Angrwal et al. recently showed that actinin-4 interacts with murine double minute 2 homolog (MDM2) binding protein (MTBP) [27, 28]. MDM2 is a major negative regulator of the tumor suppressor, p53, but also has p53-independent roles in tumorigenesis [29]. Iwakuma et al. reported that MTBP suppresses tumor metastasis and revealed an endogenous protein-protein interaction between actinin-4 and MTBP [28]. They showed that constitutive overexpression of actinin-4 in two different osteosarcoma cell lines, SaO2-LM7 (p53 null) and U2OS (p53 wild-type), increases the migration potential in both cell lines as expected. However, concomitant overexpression of MTBP significantly decreases the potential for cell migration that is mediated by overexpression of actinin-4 in both cell lines [27, 28]. Thus, MTBP inhibits cell migration that is mediated by overexpression of actinin-4 independent of p53.

In addition, actinin-4 is overexpressed in colorectal cancer [22, 23], pancreatic cancer [24, 25], ovarian cancer [26], osteosarcoma [27, 28], lung cancer [30-33], oral squamous cell carcinoma [34], salivary gland carcinoma [35], bladder cancer, breast cancer [36, 37], and esophageal cancer [38]. Reports describing overexpression of actinin-4 in association with metastasis and malignant phenotypes in cancers are summarized in Table 1 . The biological function and binding partners of actinin-4 that are associated with cell invasion are shown in Fig. 2.

\section{Amplification of ACTN4 in cancer and clinical utility as a biomarker for decisions regarding the therapeutic strategy}

Although overexpression of actinin-4 protein has been reported in several types of cancers, the cause of overexpression is not clearly understood. If overexpression is due to a genetic alteration in ACTN4, an oncogene may be actively associated with cancer invasion and metastasis. ACTN4 is located on chromosome 19q13, and amplification of the 19q13.1 locus has been reported frequently in several cancers including pancreatic and ovarian cancers [39-47]. We used specific fluorescence in situ hybridization (FISH) of ACTN4 to investigate ACTN4 amplifications in patients with pancreatic cancer [24]. ACTN4 amplifications occurred in 38\% of patients with invasive ductal adenocarcinoma of the pancreas with protein overexpression of actinin-4 [24]. Patients with ovarian cancer and ACTN4 amplification have been observed, and patients with stage III and IV disease with gene amplification show significantly worse overall survival than patients without gene amplification [48]. The status of gene amplification may more accurately predict the outcome of patients with stage III and IV ovarian cancer than immunohistochemical analysis with the antiactinin-4 antibody. In addition, positive statistical significance between ACTN4 amplification and the efficacy of post-operative chemotherapy was seen in patients with stage III and IV ovarian cancer [48, 49].

The clinical benefits of ACTN4 amplification as a prognostic factor are also observed in stage I adenocarcinoma of the lung and salivary gland carcinoma, and ACTN4 amplification is a stricter prognostic biomarker 
Table 1 Representative reports describing the importance of actinin-4 in malignant tumors

\begin{tabular}{|c|c|}
\hline Type of malignant tumor & Observations \\
\hline Brain tumors & $\begin{array}{l}\text { 1. Correlation between histological grade and protein expression of actinin-4 in gliomas [81] } \\
\text { 2. Association of actinin-4 with cell migration in gliomas [82] } \\
\text { 3. Overexpression of actinin-4 in high-grade astrocytomas [83] }\end{array}$ \\
\hline Head and neck cancer & $\begin{array}{l}\text { 4. Positive correlation between ACTN4 amplification and the histological grade of salivary gland carcinomas. The impor- } \\
\text { tance of ACTN4 amplification as a prognostic biomarker in salivary gland carcinomas [35] } \\
\text { 5. Positive correlation between invasive classification of oral squamous cell carcinoma and protein expression of actinin-4 } \\
\text { [34] } \\
\text { 6. Correlation between histological grade and protein expression in thyroid cancer [84] }\end{array}$ \\
\hline Lung cancer & $\begin{array}{l}\text { 7. Utility of ACTN4 amplification as a prognostic biomarker for stage I adenocarcinoma of the lung [50] } \\
\text { 8. Overexpression of actinin-4 mRNA in NSCLC [31] } \\
\text { 9. Identification of a splice variant of actinin-4 in SCLC as a cancer testis antigen [30]. Utility of a splice variant of actinin-4 in } \\
\text { the lung as a prognostic biomarker for high-grade malignant neuroendocrine tumors [33] } \\
\text { 10. Expression of actinin-4 in blood samples of patients with NSCLC and utility as a diagnostic biomarker for NSCLC [85] }\end{array}$ \\
\hline Breast cancer & $\begin{array}{l}\text { 11. Identification of actinin-4 as a novel actin-bundling protein, and utility of actinin-4 as a prognostic biomarker for inva- } \\
\text { sive ductal breast cancer }[13] \\
\text { 12. Summary of actinin-4 as a translational coactivator in breast cancer }[15,65] \\
\text { 13. Identification of protein-protein interactions between estrogen receptors and actinin-4 }[70]\end{array}$ \\
\hline Esophageal cancer & 14. Overexpression of actinin-4 according to clinical stage in esophageal cancer [74] \\
\hline Pancreatic cancer & $\begin{array}{l}\text { 15. First evidence of ACTN4 amplification in cancer. Identification of actinin-4 overexpression in patients with invasive } \\
\text { ductal adenocarcinoma of the pancreas with poor prognosis [24] } \\
\text { 16. Clinical utility of ACTN4 amplification as a predictive biomarker for chemoradiotherapy in LAPC [57] } \\
\text { 17. Association of actinin-4 with invadopodia in pancreatic cancer [25] }\end{array}$ \\
\hline Colorectal cancer & $\begin{array}{l}\text { 18. Identification of overexpression of actinin- } 4 \text { in areas of EMT in colorectal cancer [22] } \\
\text { 19. Involvement of actinin-4 in the formation of cellular protrusions that are associated with invasion and migration [23] }\end{array}$ \\
\hline Ovarian cancer & $\begin{array}{l}\text { 20. Identification of actinin-4 overexpression in ovarian cancer, and correlation between actinin-4 overexpression and } \\
\text { overall survival in patients with ovarian cancer [26] } \\
\text { 21. Utility of ACTN4 amplification as a prognostic biomarker in ovarian cancer [48] } \\
\text { 22. Accumulation of ACTN4 amplification in high-grade clear cell carcinoma of ovarian cancer [49] } \\
\text { 23. Identification of ACTN4 amplification in fallopian tube carcinomas [86] }\end{array}$ \\
\hline Bladder cancer & $\begin{array}{l}\text { 24. Reduced invasive ability with ACTN4 siRNA in bladder cancer cell lines [36] } \\
\text { 25. Correlation between histological grade in bladder cancer and actinin-4 protein expression [37] }\end{array}$ \\
\hline Prostate cancer & $\begin{array}{l}\text { 26. Protein complex that includes actinin-4 and androgen receptor in the nucleus. Actinin-4 protein expression is reduced } \\
\text { in the nucleus of high-grade prostate cancer [80] }\end{array}$ \\
\hline Melanoma & 27. Association of actinin-4 with amoeboid-type invasiveness of melanoma cells [87] \\
\hline Leukemia & $\begin{array}{l}\text { 28. Identification of the fusion gene MLL-ACTN4 in adult CD10-negative B-cell precursor acute lymphoblastic leukemia [88, } \\
\text { 89] }\end{array}$ \\
\hline Osteosarcoma & 29. Protein-protein interactions between MTBP and actinin-4 in osteosarcoma $[27,28]$ \\
\hline
\end{tabular}

than immunohistochemistry for overall survival in these patients.

Although the clinical benefit of adjuvant chemotherapy in patients with non-small cell lung cancer (NSCLC) who have undergone complete surgical resection has been observed in stage II-IIIA in some prospective clinical trials, the benefit has not been seen in stage I NSCLC [5052]. If patients with stage I adenocarcinoma of the lung with potential metastasis can be identified with ACTN4 amplification of surgical specimens, adjuvant chemotherapy for such patients may have a clinical benefit in terms of patient selection.

Compared to prognostic biomarkers, predictive biomarkers to select a specific treatment strategy by evaluating the metastasis ability are urgently needed. For example, local treatment such as surgery and radiotherapy could be effective in patients without distant metastases. However, local therapies are not sufficiently effective for metastatic lesions. Patients with micrometastasis, which cannot be detected with imaging, should not undergo local therapy. Treatment options for locally advanced pancreatic cancer (LAPC) include chemotherapy alone, induction chemotherapy followed by chemoradiotherapy (CRT), or definitive CRT. Numerous randomized trials have been performed to compare the survival benefit of chemotherapy alone and CRT for LAPC [53, 54]. Results have been contradictory, and the most effective treatment has not been defined for patients with LAPC $[55,56]$. Radiotherapy involving the primary site does not have sufficiently high impact for patients 


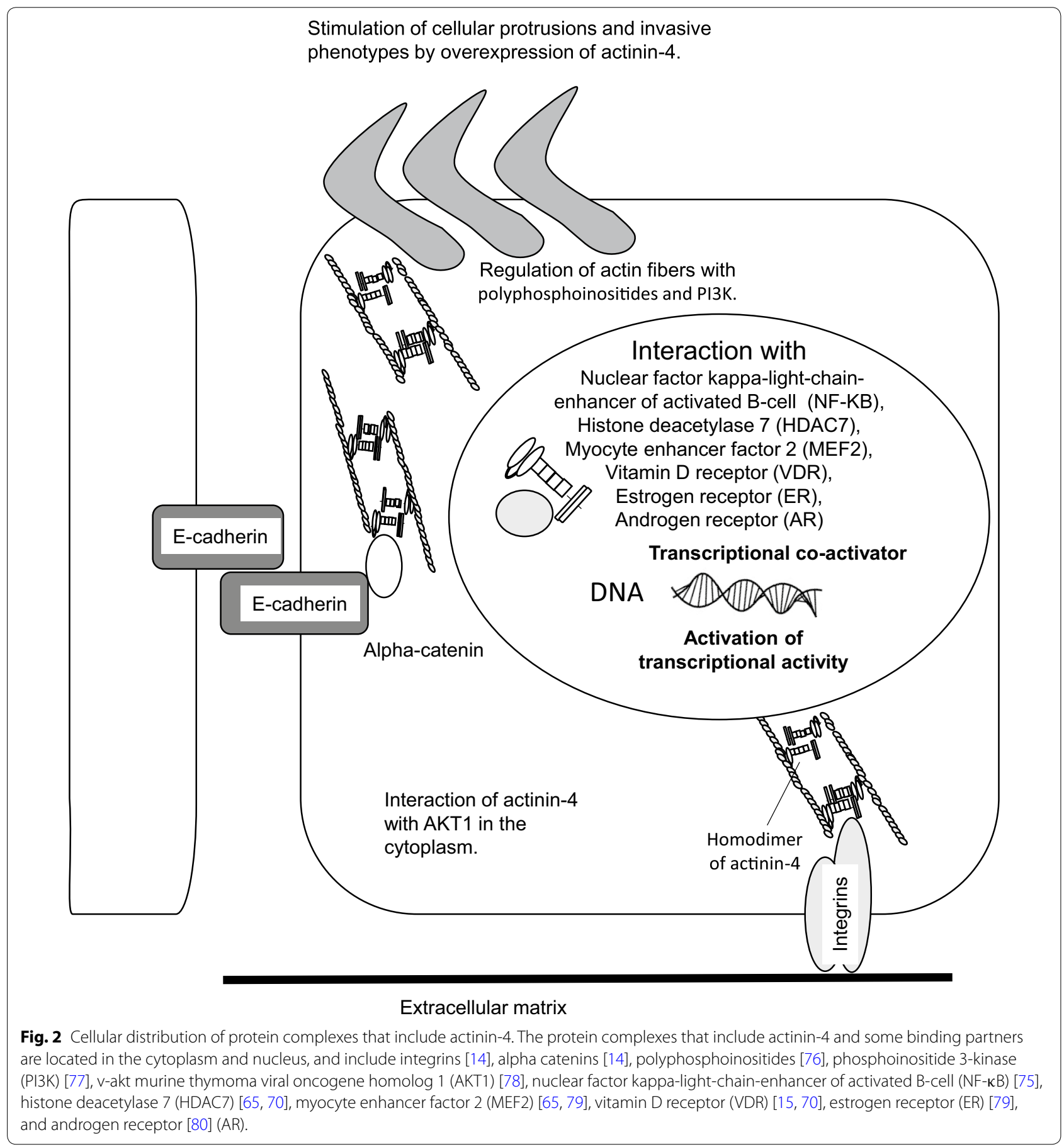

with occult distant metastasis, because radiotherapy does not treat distant metastatic lesions. However, imaging technology to accurately detect extremely small micrometastatic lesions has not been developed. Therefore, identification of biomarkers that can accurately evaluate the metastatic potential of biopsy samples from patients with LAPC will be very important for deciding the best personalized therapeutic strategy.
We used biopsy specimens and FISH analysis to retrospectively investigate the ACTN4 copy number in patients with LAPC who underwent chemotherapy or CRT [57]. In such patients who underwent CRT, those with a normal ACTN4 copy number showed a better prognosis for overall survival than patients with an increased ACTN4 copy number. However, in patients who underwent chemotherapy, no statistically significant 
difference was observed between increased and normal $A C T N 4$ copy numbers. Thus, ACTN4 may be a potential biomarker for metastatic ability and for predicting the effectiveness of CRT in LAPC [57].

\section{Specific expression of an alternative splice variant of ACTN4 in small cell lung cancer (SCLC) and mutation in focal segmental glomerular sclerosis (FSGS)}

A tumor-specific alternative splice variant of ACTN4 was found in SCLC [30]. Exon 8 of ACTN4 is skipped in this variant, and another exon is inserted in its place (ACTN4-SpEx8), resulting in the changes N249G, A251L, and S264C in exon 8 [30]. Among normal tissues and various cancer cell lines, we observed expression of ACTN4-SpEx8 only in a SCLC cell line and normal testis. Thus, ACTN4-SpEx8 is considered a cancer testis antigen. We established a specific antibody against ACTN4-SpEx8 and observed protein expression in SCLC and large cell neuroendocrine carcinoma (LCNEC) with immunohistochemistry among pathological samples of adenocarcinoma, squamous cell carcinoma, LCNEC, carcinoid, and SCLC. Patients with SCLC and LCNEC and ACTN4-SpEx8 protein expression have a worse outcome for overall survival than patients without such expression [33]. The altered amino acids, N249G, A251L, and S264C, are very close to the mutations that are observed in familial FSGS $[58,59]$, which occur in exon 8 of ACTN4 and result in the changed amino acids K255E and T259I. The threedimensional structure of ACTN2 has been studied in detail [60], and the mutated sites are located on the surface of the separation between the $\mathrm{CH} 1$ and $\mathrm{CH} 2$ domains. For actinin to bind to actin, the three-dimensional structure of the $\mathrm{CH} 1$ and $\mathrm{CH} 2$ domains of actinin changes from a closed to an open conformation [6163]. The substitution of amino acids in ACTN4-SpEx8 and the ACTN4 mutation in familial FSGS may affect the conformation of these domains.

Moreover, alteration of the affinity of actinin-4 for binding to actin filaments may be an important factor in the poor prognosis of SCLC and the effacement of foot processes in the podocytes of the glomerulus in FSGS. Recently, Ehrlicher and Pollak et al. demonstrated that in FSGS, a K255E mutation in ACTN4 changes the cellular biological properties in which increasing the affinity for actin increases cellular forces and work and decreases cellular movement. This type of mutation in this part in ACTN4 affects actinin binding kinetics to modulate cellular dynamics and force generation, and suggests the mechanisms by which such physical defects lead to human diseases [64].

\section{The role of actinin- 4 as a transcriptional coactivator in cancer}

Aberrant transcripts that fail to regulate the expression of mRNA are a cause of cancer development. Transcription of mRNA is strictly regulated in normal cells. Nuclear localization of actinin-4 is frequently observed in breast cancer [13], ovarian cancer [26], and SCLC [30] cells. However, the biological role of this nuclear localization is not clear, although a novel function other than cancer invasion is likely.

Early observation of actinin- 4 as a transcriptional coactivator began with a report of protein-protein interactions among actinin-4, class II histone deacetylases, and myocyte enhancer factor $2 \mathrm{~s}$ (MEF2s). A protein complex containing these three proteins increases the transcriptional activity of MEF2s. Chakraborty and Kao's group provided the first evidence that actinin- 4 plays a role as a transcriptional coactivator [65]. Moreover, they reported the important roles of actinin- 4 in breast cancer cell nuclei. Nuclear hormone receptors including the vitamin $\mathrm{D}$ receptor and steroid hormone receptors such as the estrogen receptor (ER) are ligand-activated transcription factors that control homeostasis, cell differentiation, proliferation, and development [66-68]. In particular, the ER plays a very important role in the development of breast cancer, and Tamoxifen, a competitive inhibitor of ERs, is used as a molecular targeted drug in ER-positive patients [69]. Recently, Kao's group also reported that estradiol (E2) promotes recruitment of actinin-4 to the promoter of $p S 2$, an ER target gene in the ER-positive breast cancer cell line, MCF7 [70, 71]. The fact that actinin-4 regulates ER-alpha-mediated transcriptional activation suggests that actinin-4 may play a role in E2-mediated regulation of breast cancer cell proliferation. In fact, decreased actinin-4 protein expression due to siRNA in MCF7 cells significantly reduces E2-mediated induction of ER-alpha target genes and abolishes estrogen-mediated proliferation of cancer cells [70]. In addition, actinin-4 and ER interact [71], suggesting that actinin-4 functions as a transcriptional co-activator with ER-alpha in some subtypes of breast cancer [15].

Nuclear factor-kappa B (NF- $\kappa \mathrm{B})$ is a transcription factor that regulates cell proliferation, the immune response, cell differentiation, and apoptosis by controlling the expression of mRNA for genes encoding inflammatory cytokines, chemokines, and adhesion molecules [72, 73]. Babakov et al. reported that actinin-4 and NF-кB change their cellular localization from the cytoplasm to the nucleus when actin fibers are disrupted by cytochalasin D. The interaction between actinin- 4 and NF- $\mathrm{kB}$ was demonstrated with immunoprecipitation following epidermal growth factor or tumor necrosis factor-alpha 
(TNF-alpha) stimulation [74]. Zaho et al. also clearly demonstrated that actinin-4 expression is essential for the transcriptional activity of NF- $\mathrm{BB}$ in the presence of TNF-alpha [75]. The NF- $\kappa B$ and TNF-alpha pathway is important for cancer development, during which actinin-4 may play an important role in regulating transcription events through the NF- $\kappa B$ pathway. The biological functions of actinin- 4 as a transcriptional co-activator are summarized in Fig. 2.

Although the nuclear localization of actinin-4 was reported in breast cancer, ovarian cancer, prostate cancer, and SCLC, a correlation between the localization of actinin -4 and clinical findings of patients with cancer is not clearly understood. The biological mechanisms of the translocation of actinin-4 to the nucleus from the cytoplasm should be clarified for innovative drug development for actinin- 4 .

\section{Conclusion and future perspective}

Here we described the biological roles of actinin-4, which is closely associated with cancer invasion and cell motility. Overexpression of actinin-4 protein and ACTN4 amplification are biomarkers for evaluating the potential metastatic ability in an individual patient with cancer, and actinin-4 expression may be useful for selecting the optimal therapy for patients. In particular, predicting late metastasis after surgery is an important clinical issue. To utilize actinin- 4 as a biomarker in the clinical setting, prospective clinical trials should be done.

Recent studies of actinin-4 demonstrated not only a role in cancer invasion, but also its biological role as a transcriptional co-activator. Actinin-4 is aggressively involved in the tumorigenesis of breast cancer, and this concept is attracting a lot of attention. The localization of actinin- 4 in the nucleus is very interesting in terms of tumorigenesis.

Targeted therapy for actinin 4 has not been developed. Recently, the three-dimensional structure of actinin-2 has been reported [60]. Using this information, we hope that a drug for molecular targeted therapy for actinin-4 will be developed. Although these proteins have distinct physiological and cellular functions, actinin-2 and actinin-4 share $80 \%$ similarity in amino acid sequence. Basic studies of the biology of actinin- 4 have the potential to overcome human diseases.

\footnotetext{
Abbreviations

ABD: actin-binding domain; ACTNs: alpha-actinins; CaM: calmodulin; $\mathrm{CH}$ : calponin homology; CRT: chemoradiotherapy; EMT: epithelial to mesenchymal transition; ER: estrogen receptor; FISH: fluorescence in situ hybridization; FSGS: focal segmental glomerular sclerosis; LCNEC: large cell neuroendocrine carcinoma; LAPC: locally advanced pancreatic cancer; MDM2: murine double minute 2 homolog; MTBP: murine double minute binding protein; MEF2: myocyte enhancer factor 2; NSCLC: non-small cell lung cancer; NF-кB: nuclear factor-kappa B; SCLC: small cell lung cancer; ACTN4-SpEx8: splice variant of ACTN4; TNF-alpha: tumor necrosis factor-alpha.
}

\section{Author details}

1 Department of Chemotherapy and Clinical Research, National Cancer Center Research Institute, 5-1-1 Tsukiji Chuoku, Tokyo 104-0045, Japan. ${ }^{2}$ AMED-CREST AMED, Japan Agency for Medical Research and Development, 1-7-1 Otemachi, Chiyoda, Tokyo 100-0004, Japan.

\section{Acknowledgements}

This work was supported by an Applied Research for Innovative Treatment of Cancer Grant from the Ministry of Health, Labor and Welfare of Japan [to KH]; Japan Agency for Medical Research and Development (AMED) Practical Research for Innovation Cancer Control (15ck0106101 h0002, to K. H.); P-direct [to KH]; AMED-CREST AMED, [to KH]; a Grant-in Aid for Scientific Research (B), and a Challenging Exploratory Research grant from the Ministry of Education, Culture, Sports, Science and Technology (MEXT) of Japan [to KH]; and the National Cancer Center Research and Development Fund [23-A-38, 23-A-11] [to $\mathrm{KH}]$.

\section{Compliance with ethical guidelines}

\section{Competing interests}

The author declares that he has no competing interests.

Received: 11 March 2015 Accepted: 2 July 2015

Published online: 18 August 2015

\section{References}

1. Palmer TD, Ashby WJ, Lewis JD, Zijlstra A. Targeting tumor cell motility to prevent metastasis. Adv Drug Deliv Rev. 2011;63(8):568-81.

2. Yano T, Okamoto T, Fukuyama S, Maehara Y. Therapeutic strategy for postoperative recurrence in patients with non-small cell lung cancer. World J Clin Oncol. 2014;5(5):1048-54.

3. Fidler IJ. The pathogenesis of cancer metastasis: the 'seed and soil' hypothesis revisited. Nat Rev Cancer. 2003;3(6):453-8.

4. Kedrin D, van Rheenen J, Hernandez L, Condeelis J, Segall JE. Cell motility and cytoskeletal regulation in invasion and metastasis. J Mammary Gland Biol Neoplasia. 2007;12(2-3):143-52.

5. Yamaguchi H, Miki H, Takenawa T. Neural Wiskott-Aldrich syndrome protein is involved in hepatocyte growth factor-induced migration, invasion, and tubulogenesis of epithelial cells. Cancer Res. 2002;62(9):2503-9.

6. Parsons JT, Horwitz AR, Schwartz MA. Cell adhesion: integrating cytoskeletal dynamics and cellular tension. Nat Rev Mol Cell Biol. 2010;11(9):633-43.

7. Mattila PK, Lappalainen P. Filopodia: molecular architecture and cellular functions. Nat Rev Mol Cell Biol. 2008;9(6):446-54.

8. Paz H, Pathak N, Yang J. Invading one step at a time: the role of invadopodia in tumor metastasis. Oncogene. 2014;33(33):4193-202.

9. Machesky LM. Lamellipodia and filopodia in metastasis and invasion. FEBS Lett. 2008;582(14):2102-11.

10. Morris HT, Machesky LM. Actin cytoskeletal control during epithelial to mesenchymal transition: focus on the pancreas and intestinal tract. Br J Cancer. 2015;112(4):613-20.

11. Youssoufian H, McAfee M, Kwiatkowski DJ. Cloning and chromosomal localization of the human cytoskeletal alpha-actinin gene reveals linkage to the beta-spectrin gene. Am J Hum Genet. 1990;47(1):62-72.

12. Beggs AH, Byers TJ, Knoll JH, Boyce FM, Bruns GA, Kunkel LM. Cloning and characterization of two human skeletal muscle alpha-actinin genes located on chromosomes 1 and 11. J Biol Chem. 1992;267(13):9281-8.

13. Honda K, Yamada T, Endo R, Ino Y, Gotoh M, Tsuda H, et al. Actinin-4, a novel actin-bundling protein associated with cell motility and cancer invasion. J Cell Biol. 1998;140(6):1383-93.

14. Otey CA, Carpen O. Alpha-actinin revisited: a fresh look at an old player. Cell Motil Cytoskelet. 2004;58(2):104-11.

15. Hsu KS, Kao HY. Alpha-actinin 4 and tumorigenesis of breast cancer. Vitam Horm. 2013;93:323-51.

16. Sjoblom B, Salmazo A, Djinovic-Carugo K. Alpha-actinin structure and regulation. Cell Mol Life Sci CMLS. 2008;65(17):2688-701.

17. Lopez-Novoa JM, Nieto MA. Inflammation and EMT: an alliance towards organ fibrosis and cancer progression. EMBO Mol Med. 2009;1(6-7):303-14 
18. Ono M, Sakamoto M, Ino Y, Moriya Y, Sugihara K, Muto T, et al. Cancer cell morphology at the invasive front and expression of cell adhesion-related carbohydrate in the primary lesion of patients with colorectal carcinoma with liver metastasis. Cancer. 1996;78(6):1179-86.

19. Hirohashi S. Inactivation of the E-cadherin-mediated cell adhesion system in human cancers. Am J Pathol. 1998;153(2):333-9.

20. Hirohashi S, Kanai Y. Cell adhesion system and human cancer morphogenesis. Cancer Sci. 2003;94(7):575-81.

21. Ino Y, Gotoh M, Sakamoto M, Tsukagoshi K, Hirohashi S. Dysadherin, a cancer-associated cell membrane glycoprotein, down-regulates E-cadherin and promotes metastasis. Proc Natl Acad Sci USA. 2002;99(1):365-70.

22. Honda K, Yamada T, Hayashida Y, Idogawa M, Sato S, Hasegawa F, et al. Actinin-4 increases cell motility and promotes lymph node metastasis of colorectal cancer. Gastroenterology. 2005;128(1):51-62.

23. Hayashida Y, Honda K, Idogawa M, Ino Y, Ono M, Tsuchida A, et al. E-cadherin regulates the association between beta-catenin and actinin-4. Cancer Res. 2005;65(19):8836-45.

24. Kikuchi S, Honda K, Tsuda H, Hiraoka N, Imoto I, Kosuge T, et al. Expression and gene amplification of actinin-4 in invasive ductal carcinoma of the pancreas. Clin Cancer Res Off J Am Assoc Cancer Res. 2008;14(17):5348-56.

25. Welsch T, Keleg S, Bergmann F, Bauer S, Hinz U, Schmidt J. Actinin-4 expression in primary and metastasized pancreatic ductal adenocarcinoma. Pancreas. 2009;38(8):968-76.

26. Yamamoto S, Tsuda H, Honda K, Kita T, Takano M, Tamai S, et al. Actinin-4 expression in ovarian cancer: a novel prognostic indicator independent of clinical stage and histological type. Mod Pathol Off J US Can Acad Pathol Inc. 2007;20(12):1278-85.

27. Agarwal N, Adhikari AS, Iyer SV, Hekmatdoost K, Welch DR, Iwakuma T. MTBP suppresses cell migration and filopodia formation by inhibiting ACTN4. Oncogene. 2013;32(4):462-70.

28. Iwakuma T, Agarwal N. MDM2 binding protein, a novel metastasis suppressor. Cancer Metastasis Rev. 2012;31(3-4):633-40.

29. Iwakuma T, Lozano G. MDM2, an introduction. Mol Cancer Res MCR. 2003;1(14):993-1000.

30. Honda K, Yamada T, Seike M, Hayashida Y, Idogawa M, Kondo T, et al. Alternative splice variant of actinin-4 in small cell lung cancer. Oncogene. 2004;23(30):5257-62.

31. Yamagata N, Shyr Y, Yanagisawa K, Edgerton M, Dang TP, Gonzalez A, et al. A training-testing approach to the molecular classification of resected non-small cell lung cancer. Clin Cancer Res Off J Am Assoc Cancer Res. 2003;9(13):4695-704.

32. Noro R, Honda K, Tsuta K, Ishii G, Maeshima AM, Miura N, et al. Distinct outcome of stage I lung adenocarcinoma with ACTN4 cell motility gene amplification. Ann Oncol Off J Eur Soc Med Oncol ESMO. 2013;24(10):2594-600.

33. Miyanaga A, Honda K, Tsuta K, Masuda M, Yamaguchi U, Fujii G, et al. Diagnostic and prognostic significance of the alternatively spliced ACTN4 variant in high-grade neuroendocrine pulmonary tumours. Ann Oncol Off J Eur Soc Med Oncol ESMO. 2013;24(1):84-90.

34. Yamada S, Yanamoto S, Yoshida H, Yoshitomi I, Kawasaki G, Mizuno A, et al. RNAi-mediated down-regulation of alpha-actinin-4 decreases invasion potential in oral squamous cell carcinoma. Int J Oral Maxillofac Surg. 2010;39(1):61-7.

35. Watabe Y, Mori T, Yoshimoto S, Nomura T, Shibahara T, Yamada T, et al. Copy number increase of ACTN4 is a prognostic indicator in salivary gland carcinoma. Cancer Med. 2014;3(3):613-22.

36. Koizumi T, Nakatsuji H, Fukawa T, Avirmed S, Fukumori T, Takahashi $\mathrm{M}$, et al. The role of actinin-4 in bladder cancer invasion. Urology. 2010;75(2):357-64.

37. Yoshii H, Ito K, Asano T, Horiguchi A, Hayakawa M, Asano T. Increased expression of alpha-actinin-4 is associated with unfavorable pathological features and invasiveness of bladder cancer. Oncol Rep. 2013;30(3):1073-80.

38. Fu L, Qin YR, Xie D, Chow HY, Ngai SM, Kwong DL, et al. Identification of alpha-actinin 4 and $67 \mathrm{kDa}$ laminin receptor as stage-specific markers in esophageal cancer via proteomic approaches. Cancer. 2007;110(12):2672-81.
39. Bellacosa A, de Feo D, Godwin AK, Bell DW, Cheng JQ, Altomare DA, et al. Molecular alterations of the AKT2 oncogene in ovarian and breast carcinomas. Int J Cancer. 1995;64(4):280-5.

40. Cheng JQ, Godwin AK, Bellacosa A, Taguchi T, Franke TF, Hamilton TC, et al. AKT2, a putative oncogene encoding a member of a subfamily of protein-serine/threonine kinases, is amplified in human ovarian carcinomas. Proc Natl Acad Sci USA. 1992;89(19):9267-71.

41. Kallioniemi A, Kallioniemi OP, Piper J, Tanner M, Stokke T, Chen L, et al. Detection and mapping of amplified DNA sequences in breast cancer by comparative genomic hybridization. Proc Natl Acad Sci USA 1994;91(6):2156-60.

42. Kim TM, Yim SH, Lee JS, Kwon MS, Ryu JW, Kang HM, et al. Genome-wide screening of genomic alterations and their clinicopathologic implications in non-small cell lung cancers. Clin Cancer Res Off J Am Assoc Cancer Res. 2005;11(23):8235-42.

43. Rao PH, Arias-Pulido H, Lu XY, Harris CP, Vargas H, Zhang FF, et al. Chromosomal amplifications, $3 q$ gain and deletions of $2 q 33-q 37$ are the frequent genetic changes in cervical carcinoma. BMC Cancer. 2004;4:5.

44. Ried T, Petersen I, Holtgreve-Grez H, Speicher MR, Schrock E, du Manoir $S$, et al. Mapping of multiple DNA gains and losses in primary small cell lung carcinomas by comparative genomic hybridization. Cancer Res. 1994;54(7):1801-6.

45. Staal SP. Molecular cloning of the akt oncogene and its human homologues AKT1 and AKT2: amplification of AKT1 in a primary human gastric adenocarcinoma. Proc Natl Acad Sci USA. 1987;84(14):5034-7.

46. Tang TC, Sham JS, Xie D, Fang Y, Huo KK, Wu QL, et al. Identification of a candidate oncogene SEl-1 within a minimal amplified region at 19q13.1 in ovarian cancer cell lines. Cancer Res. 2002;62(24):7157-61.

47. Thompson FH, Nelson MA, Trent JM, Guan XY, Liu Y, Yang JM, et al. Amplification of 19q13.1-q13.2 sequences in ovarian cancer. G-band, FISH, and molecular studies. Cancer Genet Cytogenet. 1996;87(1):55-62.

48. Yamamoto S, Tsuda H, Honda K, Onozato K, Takano M, Tamai S, et al. Actinin-4 gene amplification in ovarian cancer: a candidate oncogene associated with poor patient prognosis and tumor chemoresistance. Mod Pathol Off J US Can Acad Pathol Inc. 2009;22(4):499-507.

49. Yamamoto S, Tsuda H, Honda K, Takano M, Tamai S, Imoto I, et al. ACTN4 gene amplification and actinin-4 protein overexpression drive tumour development and histological progression in a high-grade subset of ovarian clear-cell adenocarcinomas. Histopathology. 2012;60(7):1073-83.

50. Strauss GM, Herndon JE 2nd, Maddaus MA, Johnstone DW, Johnson EA, Harpole DH, et al. Adjuvant paclitaxel plus carboplatin compared with observation in stage IB non-small-cell lung cancer: CALGB 9633 with the Cancer and Leukemia Group B, Radiation Therapy Oncology Group, and North Central Cancer Treatment Group Study Groups. J Clin Oncol Off J Am Soc Clin Oncol. 2008;26(31):5043-51.

51. Pisters KM, Evans WK, Azzoli CG, Kris MG, Smith CA, Desch CE, et al. Cancer Care Ontario and American Society of Clinical Oncology adjuvant chemotherapy and adjuvant radiation therapy for stages I-IIIA resectable non small-cell lung cancer guideline. J Clin Oncol Off J Am Soc Clin Oncol. 2007;25(34):5506-18.

52. Pignon JP, Tribodet H, Scagliotti GV, Douillard JY, Shepherd FA, Stephens RJ, et al. Lung adjuvant cisplatin evaluation: a pooled analysis by the LACE Collaborative Group. J Clin Oncol Off J Am Soc Clin Oncol. 2008;26(21):3552-9.

53. Chauffert B, Mornex F, Bonnetain F, Rougier P, Mariette C, Bouche $\mathrm{O}$, et al Phase III trial comparing intensive induction chemoradiotherapy (60 Gy, infusional 5-FU and intermittent cisplatin) followed by maintenance gemcitabine with gemcitabine alone for locally advanced unresectable pancreatic cancer. Definitive results of the 2000-01 FFCD/SFRO study. Ann Oncol Off J Eur Soc Med Oncol ESMO. 2008;19(9):1592-9.

54. Loehrer PJ Sr, Feng Y, Cardenes H, Wagner L, Brell JM, Cella D, et al. Gemcitabine alone versus gemcitabine plus radiotherapy in patients with locally advanced pancreatic cancer: an Eastern Cooperative Oncology Group trial. J Clin Oncol Off J Am Soc Clin Oncol. 2011;29(31):4105-12.

55. Savir G, Huber KE, Saif MW. Locally advanced pancreatic cancer. Looking beyond traditional chemotherapy and radiation. JOP J Pancreas. 2013;14(4):337-9.

56. Mian OY, Ram AN, Tuli R, Herman JM. Management options in locally advanced pancreatic cancer. Curr Oncol Rep. 2014;16(6):388. 
57. Watanabe T, Ueno H, Watabe Y, Hiraoka N, Morizane C, Itami J, et al. ACTN4 copy number increase as a predictive biomarker for chemoradiotherapy of locally advanced pancreatic cancer. Br J Cancer. 2015;112(4):704-13.

58. Kaplan J, Pollak MR. Familial focal segmental glomerulosclerosis. Curr Opin Nephrol Hypertens. 2001;10(2):183-7.

59. Kaplan JM, Kim SH, North KN, Rennke H, Correia LA, Tong HQ, et al. Mutations in ACTN4, encoding alpha-actinin-4, cause familial focal segmental glomerulosclerosis. Nat Genet. 2000;24(3):251-6.

60. Ribeiro Ede A, N Pinotsis Jr, Ghisleni A, Salmazo A, Konarev PV, Kostan J, et al. The structure and regulation of human muscle alpha-actinin. Cell. 2014;159(6):1447-60.

61. Lee SH, Weins A, Hayes DB, Pollak MR, Dominguez R. Crystal structure of the actin-binding domain of alpha-actinin-4 Lys255Glu mutant implicated in focal segmental glomerulosclerosis. J Mol Biol. 2008;376(2):317-24.

62. Liu J, Taylor DW, Taylor KA. A 3-D reconstruction of smooth muscle alpha-actinin by CryoEm reveals two different conformations at the actinbinding region. J Mol Biol. 2004;338(1):115-25.

63. Galkin VE, Orlova A, Salmazo A, Djinovic-Carugo K, Egelman EH. Opening of tandem calponin homology domains regulates their affinity for F-actin. Nat Struct Mol Biol. 2010;17(5):614-6.

64. Ehrlicher AJ, Krishnan R, Guo M, Bidan CM, Weitz DA, Pollak MR. Alphaactinin binding kinetics modulate cellular dynamics and force generation. In: Proceedings of the National Academy of Sciences of the United States of America. 2015 Apr 27. pii: 201505652. [Epub ahead of print].

65. Chakraborty S, Reineke EL, Lam M, Li X, Liu Y, Gao C, et al. Alpha-actinin 4 potentiates myocyte enhancer factor-2 transcription activity by antagonizing histone deacetylase 7. J Biol Chem. 2006;281(46):35070-80.

66. Mangelsdorf DJ, Evans RM. The RXR heterodimers and orphan receptors. Cell. 1995;83(6):841-50.

67. Mangelsdorf DJ, Thummel C, Beato M, Herrlich P, Schutz G, Umesono K, et al. The nuclear receptor superfamily: the second decade. Cell. 1995;83(6):835-9.

68. Francis GA, Fayard E, Picard F, Auwerx J. Nuclear receptors and the control of metabolism. Annu Rev Physiol. 2003;65:261-311.

69. Jordan VC, Brodie AM. Development and evolution of therapies targeted to the estrogen receptor for the treatment and prevention of breast cancer. Steroids. 2007;72(1):7-25.

70. Khurana S, Chakraborty S, Cheng X, Su YT, Kao HY. The actin-binding protein, actinin alpha 4 (ACTN4), is a nuclear receptor coactivator that promotes proliferation of MCF-7 breast cancer cells. J Biol Chem. 2011;286(3):1850-9.

71. Khurana S, Chakraborty S, Zhao X, Liu Y, Guan D, Lam M, et al. Identification of a novel LXXLL motif in alpha-actinin 4-spliced isoform that is critical for its interaction with estrogen receptor alpha and co-activators. J Biol Chem. 2012;287(42):35418-29.

72. DiDonato JA, Mercurio F, Karin M. NF-kappaB and the link between inflammation and cancer. Immunol Rev. 2012;246(1):379-400.

73. Tornatore L, Thotakura AK, Bennett J, Moretti M, Franzoso G. The nuclear factor kappa B signaling pathway: integrating metabolism with inflammation. Trends Cell Biol. 2012;22(11):557-66.

74. Babakov VN, Petukhova OA, Turoverova LV, Kropacheva IV, Tentler DG, Bolshakova AV, et al. RelA/NF-kappaB transcription factor associates with alpha-actinin-4. Exp Cell Res. 2008;314(5):1030-8.

75. Zhao X, Hsu KS, Lim JH, Bruggeman LA, Kao HY. Alpha-Actinin 4 potentiates nuclear factor kappa-light-chain-enhancer of activated B-cell (NF-kappaB) activity in podocytes independent of its cytoplasmic actin binding function. J Biol Chem. 2015;290(1):338-49.

76. Fukami K, Sawada N, Endo T, Takenawa T. Identification of a phosphatidylinositol 4,5-bisphosphate-binding site in chicken skeletal muscle alpha-actinin. J Biol Chem. 1996;271(5):2646-50.

77. Shibasaki F, Fukami K, Fukui Y, Takenawa T. Phosphatidylinositol 3-kinase binds to alpha-actinin through the p85 subunit. Biochem J. 1994;302(Pt 2):551-7.
78. Ding Z, Liang J, Lu Y, Yu Q, Songyang Z, Lin SY, et al. A retrovirus-based protein complementation assay screen reveals functional AKT1-binding partners. Proc Natl Acad Sci USA. 2006;103(41):15014-9.

79. Khurana S, Chakraborty S, Lam M, Liu Y, Su YT, Zhao X, et al. Familial focal segmental glomerulosclerosis (FSGS)-linked alpha-actinin 4 (ACTN4) protein mutants lose ability to activate transcription by nuclear hormone receptors. J Biol Chem. 2012;287(15):12027-35.

80. Jasavala R, Martinez H, Thumar J, Andaya A, Gingras AC, Eng JK, et al. Identification of putative androgen receptor interaction protein modules: cytoskeleton and endosomes modulate androgen receptor signaling in prostate cancer cells. Mol Cell Proteomics : MCP. 2007;6(2):252-71.

81. Fukushima S, Yoshida A, Honda K, Maeshima AM, Narita Y, Yamada T, et al. Immunohistochemical actinin-4 expression in infiltrating gliomas: association with WHO grade and differentiation. Brain Tumor Pathol. 2014;31(1):11-6.

82. Henry WI, Dubois J, Quick QA. The microtubule inhibiting agent epothilone B antagonizes glioma cell motility associated with reorganization of the actin-binding protein alpha-actinin 4. Oncol Rep. 2011;25(3):887-93.

83. Quick Q, Skalli O. Alpha-actinin 1 and alpha-actinin 4: contrasting roles in the survival, motility, and RhoA signaling of astrocytoma cells. Exp Cell Res. 2010;316(7):1137-47.

84. Tanaka N, Yamashita T, Yamamoto S, Matsunobu T, Tsuda H, Honda K, et al. Histological growth pattern of and alpha-actinin-4 expression in thyroid cancer. Anticancer Res. 2014;34(6):3157-63.

85. Wang MC, Chang YH, Wu CC, Tyan YC, Chang HC, Goan YG, et al. Alphaactinin 4 is associated with cancer cell motility and is a potential biomarker in non-small cell lung cancer. JThorac Oncol Off Publ Int Assoc Study Lung Cancer. 2015;10(2):286-301.

86. Nowee ME, Snijders AM, Rockx DA, de Wit RM, Kosma VM, Hamalainen $\mathrm{K}$, et al. DNA profiling of primary serous ovarian and fallopian tube carcinomas with array comparative genomic hybridization and multiplex ligation-dependent probe amplification. J Pathol. 2007;213(1):46-55.

87. Shao H, Li S, Watkins SC, Wells A. Alpha-Actinin-4 is required for amoeboid-type invasiveness of melanoma cells. J Biol Chem. 2014;289(47):32717-28.

88. Burmeister T, Meyer C, Schwartz S, Hofmann J, Molkentin M, Kowarz E, et al. The MLL recombinome of adult CD10-negative B-cell precursor acute lymphoblastic leukemia: results from the GMALL study group. Blood. 2009;113(17):4011-5.

89. Yang JJ, Park TS, Lee ST, Seo JY, Oh SH, Cho EH, et al. Molecular characterization and clinical course of MLL-ACTN4 rearrangement in therapyrelated hematologic malignancies. Haematologica. 2014;99(4):e49-51.

\section{Submit your next manuscript to BioMed Central and take full advantage of:}

- Convenient online submission

- Thorough peer review

- No space constraints or color figure charges

- Immediate publication on acceptance

- Inclusion in PubMed, CAS, Scopus and Google Scholar

- Research which is freely available for redistribution

Submit your manuscript at

www.biomedcentral.com/submit
C Biomed Central 